\title{
AUMENTO DE CAPACIDADE DE REFRIGERAÇÃO EM UNIDADES DE SEPARAÇÃO DE AR POR MEIO DE EXTENSÃO DOS LIMITES OPERACIONAIS*
}

Rene Guilherme Lopes ${ }^{1}$

\section{Resumo}

A refrigeração necessária a separação e liquefação dos gases do ar em uma planta de separação de ar do tipo $P L$ de fabricação Praxair, é produzida em um equipamento denominado "Bridge Machine". Foi identificada a oportunidade de operar este equipamento acima da capacidade nominal, porém havia algumas restrições para atingir a pressão necessária, tais como: a linha de descarga, a calibração da PSV, a MAWP (pressão máxima te trabalho admissível) do aftercooler e PHX (trocador de calor principal da Planta) e de outras linhas no processo. Para aumentar a produção na Bridge Machine, fez-se necessário requalificar a MAWP do aftercooler e do PHX, além de substituir as linhas de descarga e recalibrar a PSV, assim podendo trabalhar com a pressão máxima possível.

Palavras-chave: Bridge machine; Refrigeração; Otimização.

\section{REFRIGERATION CAPACITY IMPROVEMENT EXTENDING OPERATIONAL LIMITS}

\section{Abstract}

The refrigeration at a PL type plant manufactured by Praxair, is produced in an equipment named "Bridge Machine". It was identified an opportunity to run this machine at a pressure higher than design, but there were restrictions to the necessary pressure in the discharge lines, such as: the PSV calibration, the MAWP of the aftercooler and PHX exchanger, as well the process lines. In order to upgrade the Bridge Machine production, some actions have been done like requalifying the aftercooler and PHX MAWP, replacement of some lines and recalibration of the PSV in order to work at the maximum pressure as possible.

Keywords: Bridge machine; Refrigeration; Optimization; PHX.

1 Engenheiro Elétrico, Engenheiro, Produtividade, Centro Universitário Salesiano de São Paulo, Americana, SP, Brasil.

* Contribuição técnica ao $35^{\circ}$ Seminário de Balanços Energéticos Globais e Utilidades e $29^{\circ}$ Encontro de Produtores e Consumidores de Gases Industriais, 13 a 15 de agosto de 2014, São Paulo, SP, Brasil. 


\section{INTRODUÇÃO}

Nas unidades de separação de ar a refrigeração pode ser gerada através de um sistema de compressão em série, primeiro um compressor baseload, seguido de um compressor booster, e uma turbina onde a refrigeração é gerada. Esse sistema é conhecido por Bridge Machine (BRIM).

Historicamente, a planta modelo $\mathrm{PL}$ (product Line) em questão, apresentava limitações para aumento da pressão de descarga do booster da BRIM (Bridge Machine) devido ao set da PSV (válvulas de alívio) restringir esta operação, impossibilitando explorar a máxima queda de pressão na turbina, o que que geraria mais refrigeração à planta.

Diante deste cenário, foram realizados estudos pela equipe de Produtividade (Grupo Eficiência Operacional White Martins) em conjunto com Praxair, visando elaborar uma estratégia para resolução do problema.

O cenário estudado e proposto foi a requalificação do circuito a jusante a BRIM aftercooler, tubulações, PSV e PHX - para operação com a nova pressão.

\section{MATERIAIS E MÉTODOS}

Foram feitas modificações e trocas das linhas (figura 1), além de requalificações nos equipamentos a jusante do compressor da bridge machine. Na figura 1, o trecho visualizado tem maior espessura que o anterior. Na figura 2 é possível observar os principais equipamentos que se localizam entre a descarga do compressor e a entrada da turbina, tais como os trocadores de calor (aftercooler do booster e o $\mathrm{PHX)}$, as linhas e PSV.

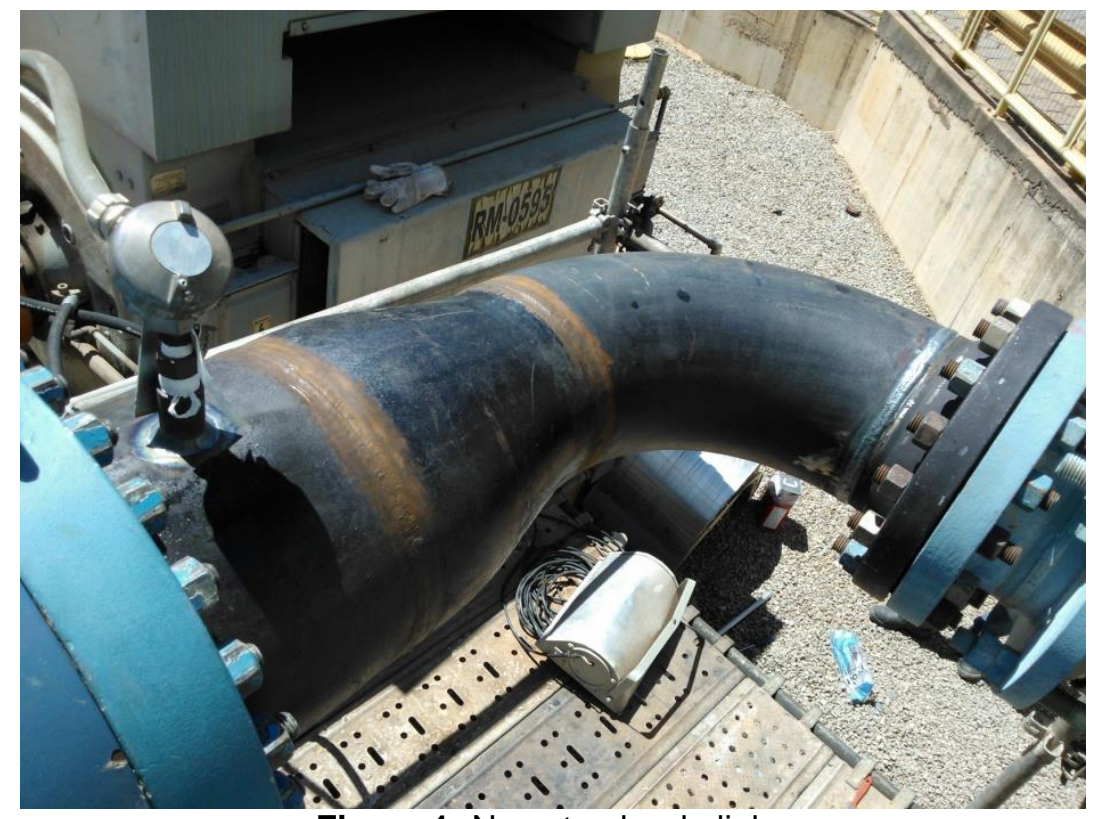

Figura 1: Novo trecho de linha

* Contribuição técnica ao $35^{\circ}$ Seminário de Balanços Energéticos Globais e Utilidades e $29^{\circ}$ Encontro de Produtores e Consumidores de Gases Industriais, 13 a 15 de agosto de 2014, São Paulo, SP, Brasil. 

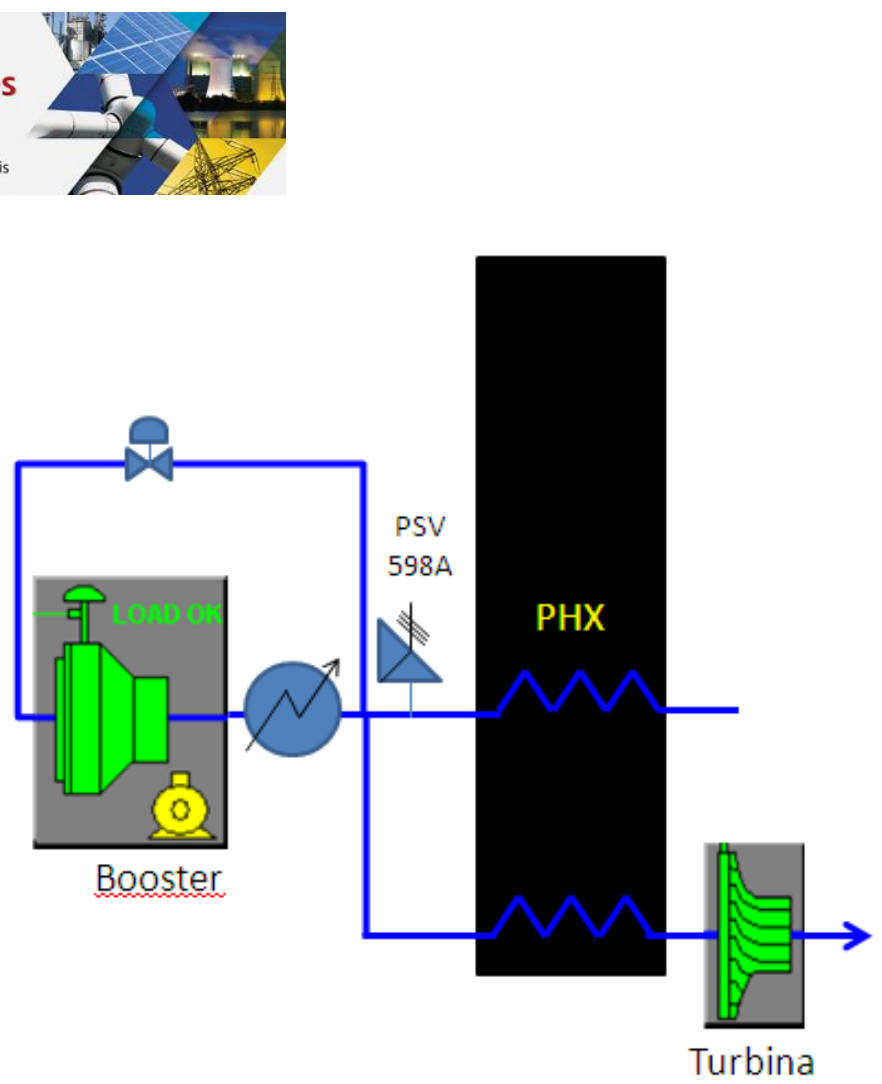

Figura 2: Descritivo Geral do processo

A requalificação do $\mathrm{PHX}$ foi estabelecida pelo fabricante Chart, através de novo laudo, enquanto as requalificações das tubulações e elementos de linha foram estabelecidas pela Engenharia White Martins Brasil através de um laudo técnico que também definiu a obrigatoriedade de substituição de um trecho de saída do aftercooler da Bridge Machine.

Por último, a requalificação do aftercooler seria estabelecida através de um teste hidrostático, além da recalibração da PSV, que foi realizada no mesmo momento.

\section{RESULTADOS E DISCUSSÃO}

Com a execução do projeto, as mudanças realizadas proporcionaram o incremento na pressão de entrada na turbina, assim como pode-se observar na figura 3.

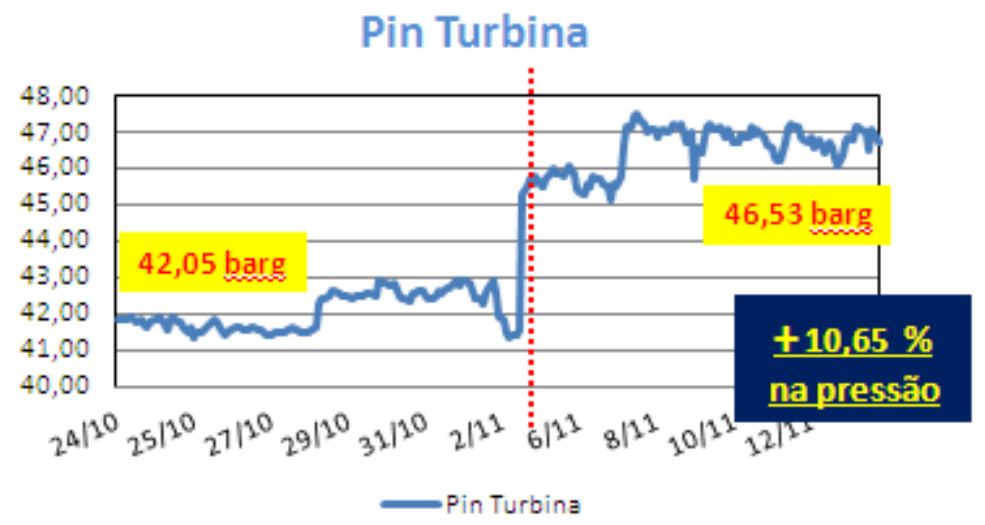

Figura 3: Aumento da pressão

O aumento da pressão de entrada na turbina é diretamente proporcional ao incremento na refrigeração, isto é, a alteração positiva do patamar de operação da Bridge Machine resultou em uma nova e otimizada capacidade de produção, assim como representado na figura 4 .

* Contribuição técnica ao $35^{\circ}$ Seminário de Balanços Energéticos Globais e Utilidades e $29^{\circ}$ Encontro de Produtores e Consumidores de Gases Industriais, 13 a 15 de agosto de 2014, São Paulo, SP, Brasil. 


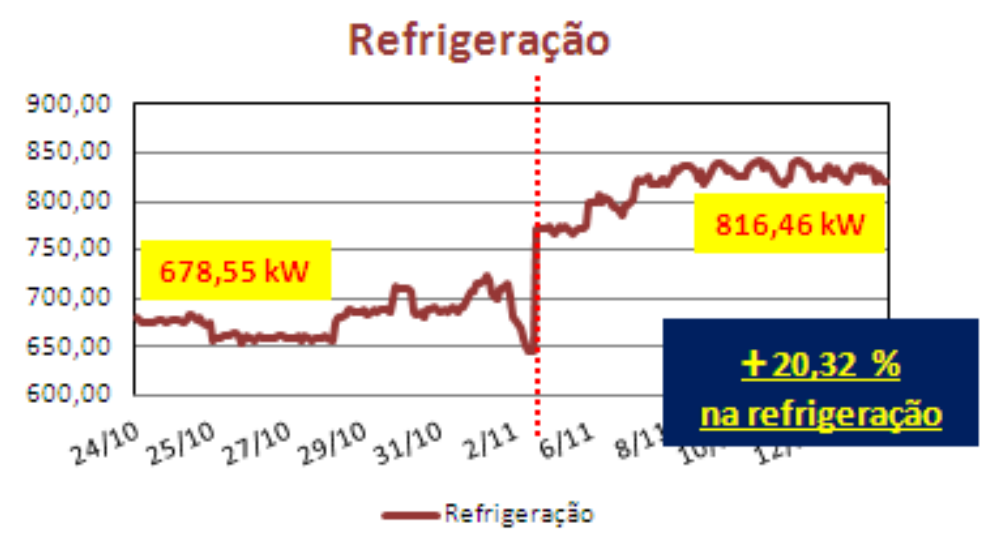

Figura 4: Aumento da refrigeração

O valor investido no projeto foi relativamente baixo, gerando um payback simples menor que dois meses. Todo o processo, onde a requalificação do trocador de calor principal da planta foi o item chave, durou 7 meses. Os benefícios gerados puderam ser verificados tanto no consumo específico da planta, redução de $6 \%$, assim como no aumento de produção, 8 toneladas por dia de oxigênio líquido, equivalente a 110 carretas por ano.

Os benefícios foram gerados sem acréscimo de energia.

\section{CONCLUSÃo}

Após um ano de implementado, o projeto continua desempenhando em sua máxima performance, uma vez que os novos parâmetros de pressão foram parametrizados no sistema de controle automático da planta. O reporte dos resultados foi validado financeiramente constando nos resultados de produtividade da empresa.

Existem outras quatro plantas PL com uma disposição de equipamentos similar. Assim, há a possibilidade de replicar este o projeto. Cada caso necessita ser analisado especificamente.

\section{Agradecimentos}

Um agradecimento especial para aqueles que realizaram a implementação do projeto na unidade, dentre eles Jaider Oliveira (Supervisor de Produção), Alison Patrocinio (Técnico de Produção), Paulo Aranha (Técnico em Mecânica), Alexandre Rezende (Técnico em Instrumentação), Evandro Souza (Técnico de Produção), Rodrigo Avila (Técnico de Produção).

\section{FONTE}

UNISIM Process Modeling Software.

* Contribuição técnica ao $35^{\circ}$ Seminário de Balanços Energéticos Globais e Utilidades e $29^{\circ}$ Encontro de Produtores e Consumidores de Gases Industriais, 13 a 15 de agosto de 2014, São Paulo, SP, Brasil. 